\title{
PROSPECTIVE STUDY OF POSTOPERATIVE WHOLE BREAST RADIOTHERAPY FOR PATIENTS WITH LARGE AND PENDULOUS BREAST: A CLINICAL AND DOSIMETRIC COMPARISONS BETWEEN SUPINE AND PRONE POSITIONS
}

Izabela Lourenço Silva Fernandes¹, José Maria Fernandes Júnior¹, Marcelo Luvizotto Alcântara de Pádua', Marília Ferreira Andrade', Nayara Ferreira Cunha', Marcela Carrijo Setti', Fredstone Rodrigues da Cunha'

${ }^{1}$ COT - Centro Oncológico do Triângulo - Uberlândia (MG), Brazil.

Introduction: Adjuvant radiotherapy is the standard treatment following breast conserving surgery (BCS). Irradiation after BCS in women with large and/or pendulous breasts is a challenge for radiation oncologists. Increased radiation related toxicity and worse cosmetic outcome was found in these patients. Prone breast irradiation aims to improve some of the technical limitations associated with treating large and pendulous breasts and it may limit radiation doses to organs at risk (OAR) such as lung and heart. Objectives: The goal of this study is to compare dosimetric parameters in prone versus supine position in a cohort of women with pendulous breasts receiving Radiotherapy after conservative surgery and the severity of cutaneous toxicity in these patients. Methods: Early-stage breast cancer patients with large or pendulous breasts undergoing BCS participated in this study. CT-based treatment plans were made in each position, and various dosimetric parameters for the breast and OAR were calculated to compare the supine and prone radiotherapy plans. The actual treatment was delivered in the position regarded as better. The patients were followed during the treatment to evaluate the skin and the grade of radiodermatitis were registered. Results: From 2016 to 2017, 26 patients were prospectively accrued. The median lung dose and the V20 (lung volume that receives $20 \mathrm{~Gy}$ ) were significantly lower in the prone position $(\mathrm{p}<0.0010)$. The homogeneity index and the contralateral breast dose were significantly lower in the supine position ( $\mathrm{p}=0,006$ and $\mathrm{p}<0,01$ respectively). The other variables (V25 and heart median dose) showed no significant differences between two positions. By comparing two plans, the prone position was chosen in $73 \%$ of the patients. In the prone position, grade 2 dermatitis were seen in $26 \%$, whereas $42.8 \%$ of patients treated in the supine position had grade 2 and no cases of grade 3 dermatitis, although without a statistical significance $(\mathrm{p}=0.33)$. Conclusions: Prone breast irradiation lowers lung dose significantly when compared to supine position. Although without a statistical significance, there was a trend towards a reduction in skin dermtititis when patients were treated in prone position. 